\title{
Clinical applications of genetic analysis and liquid chromatography tandem-mass spectrometry in rare types of congenital adrenal hyperplasia
}

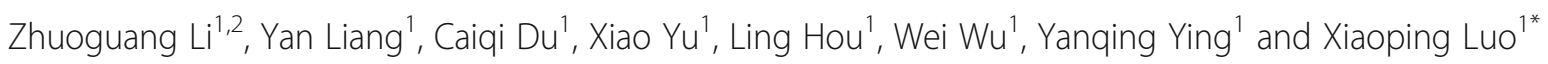

\begin{abstract}
Background: Our study aims to summarize the clinical characteristics of rare types of congenital adrenal hyperplasia (CAH) other than 21-hydroxylase deficiency (21-OHD), and to explore the clinical applications of genetic analysis and liquid chromatography tandem-mass spectrometry (LC-MS/MS) in rare CAH.

Methods: We retrospectively analysed the clinical data of 5 rare cases of CAH admitted to our hospital and summarized their clinical manifestations, auxiliary examinations, diagnosis and mutational spectrum.

Results: After gene sequencing, complex heterozygous variants were detected in all patients (2 cases were lipoid

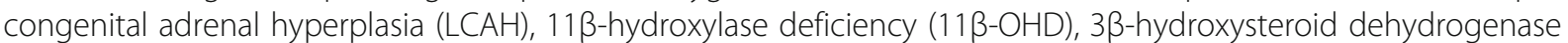
deficiency (3ß-HSD deficiency) and P450 oxidoreductase deficiency (PORD) each accounted for 1 case), which were consistent with their clinical manifestations. Among them, 4 novel variants were detected, including c. $650+2 \mathrm{~T}>\mathrm{A}$ of the StAR gene, c.1145 T > C (p. L382P) of the CYP11B1 gene, c.1622C > T (p. A541V) and c.1804C > T (p. Q602 *) of the POR gene. The LC-MS/MS results for steroid hormones in patients were also consistent with their genetic variants: 2 patients with LCAH showed a decrease in all steroid hormones; $11 \beta-O H D$ patient showed a significant increase in 11-deoxycortisol and 11-deoxycorticosterone; patient with 33-HSD deficiency showed a significant increase in DHEA; and PORD patient was mainly characterized by elevated 17OHP, progesterone and impaired synthesis of androgen levels.

Conclusions: The clinical manifestations and classification of CAH are complicated, and there are cases of missed diagnosis or misdiagnosis. It's necessary to combine the analysis of clinical manifestations and auxiliary examinations for diagnosis; if necessary, LC-MS/MS analysis of steroid hormones or gene sequencing is recommended for confirming diagnosis and typing.
\end{abstract}

Keywords: Congenital adrenal hyperplasia, Lipoid congenital adrenal hyperplasia, $11 \beta$-hydroxylase deficiency, 3 3 hydroxysteroid dehydrogenase deficiency, P450 oxidoreductase deficiency

\footnotetext{
* Correspondence: xpluo@tjh.tjmu.edu.cn

'Department of Pediatrics, Tongji Hospital, Tongji Medical College, Huazhong University of Science and Technology, Wuhan, China

Full list of author information is available at the end of the article
}

C C The Author(s). 2021 Open Access This article is licensed under a Creative Commons Attribution 4.0 International License, which permits use, sharing, adaptation, distribution and reproduction in any medium or format, as long as you give appropriate credit to the original author(s) and the source, provide a link to the Creative Commons licence, and indicate if changes were made. The images or other third party material in this article are included in the article's Creative Commons licence, unless indicated otherwise in a credit line to the material. If material is not included in the article's Creative Commons licence and your intended use is not permitted by statutory regulation or exceeds the permitted use, you will need to obtain permission directly from the copyright holder. To view a copy of this licence, visit http://creativecommons.org/licenses/by/4.0/. The Creative Commons Public Domain Dedication waiver (http://creativecommons.org/publicdomain/zero/1.0/) applies to the data made available in this article, unless otherwise stated in a credit line to the data. 


\section{Background}

Congenital adrenal hyperplasia (CAH) is a group of autosomal recessive inherited diseases caused by congenital defects of essential enzymes in the synthesis of steroid hormones, characterized by adrenocortical insufficiency, accompanied by (or not accompanied) hyperandrogenism [1, 2]. The incidence of $\mathrm{CAH}$ has been reported to be approximately $1 / 14000-1 / 18000$ worldwide [2] and 1/20815-1/25757 in China [3]. According to defective enzymes (genes) [4], CAH can be divided into 7 types, among which 21-OHD is the most common type (90 to $95 \%$ ), $11 \beta-$ OHD accounts for approximately $5-8 \%, 17-\mathrm{OHD}$ and $3 \beta-\mathrm{HSD}$ deficiency accounts for less than $1 \%$, and other types of $\mathrm{CAH}$ are relatively rare worldwide (LCAH: about 200 cases, PORD: about 130 cases, P450cc deficiency: only about 30 cases).

Due to the diversity and similarity of clinical manifestations, there are certain difficulties in the diagnosis of rare types of $\mathrm{CAH}$, especially for their classification. Gene sequencing is a better verification and supplement for routine examinations, other types of $\mathrm{CAH}$ except 21OHD can be well detected using next-generation sequencing technology [5, 6]. However, sometimes gene sequencing may take a long time and delay the patient's treatment $[1,2]$. Therefore, reliable clinical diagnosis is also critical. In recent years, with the application of LCMS/MS in the detection of steroid hormones, early diagnosis and classification of $\mathrm{CAH}$ have become possible. In a study performed by Janzen in 2012 [7], LC-MS/MS was used to detect steroid hormone levels in patients with $\mathrm{CAH}$, and they found that unlike 21-OHD patients, the 11-deoxycortisol level of patients with $11 \beta-O H D$ was significantly increased, while the 21-deoxycortisol level was almost normal. It's believe that through the analysis of the corresponding steroid hormone profile, a preliminary differential diagnosis can be made between different types of $\mathrm{CAH}$.

In order to further understand the genotypic and clinical characteristics of rare types of $\mathrm{CAH}$, so as to facilitate early diagnosis and treatment, 5 Chinese patients with CAH were recruited retrospectively and their clinical features were analysed.

\section{Methods and materials Subjects}

According to the CAH guidelines of the Pediatric Society of Chinese Medical Association in 2016 and the American Academy of Pediatrics Endocrine in 2018(1; 2 ), we included 5 patients with $\mathrm{CAH}$ admitted to our hospital who were clinically presumed and genetically confirmed. Clinical data were collected, including history, clinical manifestations, and auxiliary examinations (adrenocortical function (including 17OHP (17 $\alpha$-hydroxyprogesterone), A4(androstenedione), DHEAS (dehydroepiandrosterone sulfate), $\mathrm{T}$ (testosterone), $\mathrm{F}$ (cortisol) and ACTH (adrenocorticotropic hormone), chemiluminescence immunoassay), electrolytes, hepatic and renal function, fasting glucose, etc.). Bone age assessment, adrenal Doppler ultrasound or CT and chromosome karyotype were also collected if available.

\section{LC-MS/MS analysis of steroid hormones}

Our patients were treated with hydrocortisone (10-15 $\mathrm{mg} / \mathrm{m}^{2} / \mathrm{d}$, divided into 3-4 doses) after clinical diagnosis. During recent follow-ups, LC-MS/MS was used to detect steroid hormone levels. After obtaining informed consent, a $2 \mathrm{~mL}$ blood sample from each patient was sent to Kindstar Global Co., Ltd. (Wuhan) for steroid hormone detection by LC-MS/MS. First, after obtaining serum samples isolated from blood samples $(3000 \mathrm{r} / \mathrm{min}, 3$ min), 8 internal standard solutions (progesterone- $d 9$, $17 \alpha-\mathrm{OH}$-progesterone-d8, testosterone-d3, DHEA-d6, aldosterone- $\mathrm{d} 4, \quad$ corticosterone- $\mathrm{d} 4, \quad$ cortisol- $\mathrm{d} 4$, deoxycortisone-d5) and MTBE (methyl tertiary butyl ether) were added to serum samples for extraction. Next, the supernatant of the above mixture was obtained by shaking, mixing and freezing centrifugation $(10,000 \mathrm{r} /$ $\mathrm{min}, 3 \mathrm{~min}$ ), and then the supernatant was blown dry by the nitrogen blowing instrument. Finally, 50\% methanolaqueous solution was added to the above sample for reconstitution, the supernatant was obtained after centrifugation $(10,000 \mathrm{r} / \mathrm{min}, 3 \mathrm{~min})$ and used for subsequent chromatographic separation. The chromatographic parameters were as follows: (1)Separation column: Shimpack GIST C18 $(2 \mu \mathrm{m}, 100 * 2.1 \mathrm{~mm})$; (2)Mobile phase: solvent A (0.1\% formic acid solution) and solvent B ( $0.1 \%$ formic acid-methanol solution), the gradient elution mode was used. Mass spectrometry analysis: Electrospray ionization (ESI) mode was used for ionization, positive ion multiple reaction monitoring mode (MRM) was used for scanning, and quantitative analysis was performed using the internal standard method. Finally, in the data analysis, Lab Solutions software was used to analyse the hormone levels of the patient's serum sample.

\section{Genetic analysis}

After obtaining informed consent, gene sequencing (Beijing MyGenostics Inc.) was performed on the probands and their parents. In addition to 7 known $C A H$ genes (CYP21A2, StAR, CYP11B1, HSD3B2, POR, CYP17A1 and CYP11A1), 37 adrenal or gonadal genes including NROB1, PRKACA, DHCR7and so on. were also tested to exclude the possibility of adrenal or gonadal abnormalities (see Supplementary Table 1). First, we fragmented 1-3 $\mu \mathrm{g}$ of genomic DNA, which was extracted from the sample, to an average size of $180 \mathrm{bp}$ with a Bioruptor sonicator (Diagenode). The preparation 
of DNA Library carried out by Illumina protocols mainly included end repair, adapter ligation and PCR enrichment. The amplified DNA was captured using a GenCap CAH capture kit (MyGenostics GenCap Enrichment Technologies). The DNA probes were designed to tile along the exon regions and exon-intron boundaries of the 44 target genes. After enrichment of DNA fragments, an Illumina HiSeq $\mathrm{X}$ sequencer was used for high-throughput sequencing of the captured exon region. Suspected candidate variants were screened by comprehensively considering the genetic pattern of the disease and the patient's clinical characteristics. The pathogenicity of variants was predicted according to the 2015-ACMG Standards and Guidelines [8].

\section{Results}

After gene sequencing, of the 5 patients with $\mathrm{CAH}, 2$

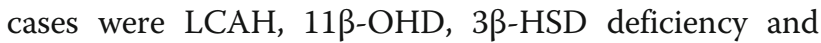
PORD each accounting for 1 case. See Table 1.

\section{Clinical manifestations}

The 2 patients with LCAH were admitted in the neonatal period due to "cyanosis and skin pigmentation throughout the body". The male patient also had occult penis and hypospadias, while no abnormalities in the vulva were found in the female patient.

The 11ß-OHD patient was first admitted at 3.5 years old due to "enlarged penis for 3 years". He had obvious acne on his face and chest, and obvious pigmentation on his vulva, accompanied by accelerated growth of height $(114.4 \mathrm{~cm},+3.54$ SDS). Blood pressure monitoring showed: $107-111 / 55-79 \mathrm{mmHg}$. His twin brother also had an enlarged penis at birth and died prematurely of an infection.

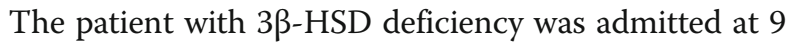
years old due to "enlarged testicles for 5 years" $(>20 \mathrm{~mL})$. He had obviously swarthy skin throughout the body, accompanied by accelerated growth of height $(143.3 \mathrm{~cm},+$ 1.36 SDS). His elder brother was also diagnosed with $3 \beta-$
HSD deficiency, with enlarged testicles and swarthy skin, and his final adult height was $150.3 \mathrm{~cm}(-3.71 \mathrm{SDS})$.

The PORD patient was admitted at 2 years old due to "external genital abnormalities for more than 1 year". An enlarged clitoris like a penis was found, and one shared opening for her vagina and urethra, but no obvious pigmentation was seen.

\section{Auxiliary examinations}

In terms of adrenocortical function (chemiluminescence immunoassay), LCAH patients manifested as a low level of all adrenal hormones with a significant increase in $\mathrm{ACTH}$; 11ß-OHD patient was mainly characterized by elevated 17OHP and androgen; $3 \beta$-HSD deficiency patient was characterized by a significant increase in DHEAS; and patient with PORD suffered 17OHP increasing slightly with normal androgen levels. See Table 1 and Supplementary Table 2 for details. The main biochemical indices of these 5 patients, such as electrolytes $(\mathrm{Na}+, \mathrm{K}+)$, hepatic and renal function and son on, were basically normal at the first visit.

In terms of BA assessment, BA of 11 $\beta-O H D$ (Chronological Age/CA: 3.5 years, BA: 13 years) and $3 \beta$-HSD deficiency (CA: 9 years, BA: 16 years) patients significantly advanced, resulting in their $\mathrm{HtSDS}_{\mathrm{BA}}$ fell far behind (5.72 SDS for $11 \beta-O H D,-4.56$ SDS for $3 \beta-H S D)$. However, the BA of PORD patient and 1 case of LCAH lagged behind their CA by 1 year, and another LCAH patient didn't undergo BA assessment because of her young age $(<2$ years).

\section{LC-MS/MS analysis of steroid hormones}

During recent follow-ups, LC-MS/MS was used to detect steroid hormone levels. See Supplementary Table 3 and Fig. 1 for details.

The 2 patients with LCAH showed a decrease in the levels of all steroid hormones because of the defect of steroidogenic acute regulatory protein (StAR protein). Because of $11 \beta$-hydroxylase deficiency, $11 \beta$-OHD patient

Table 1 Clinical characteristics of 5 patients with rare types of CAH

\begin{tabular}{|c|c|c|c|c|c|c|c|}
\hline Types & Genes & Variants & Inheritance & Pathogenicity & $\begin{array}{l}\text { First } \\
\text { visit } \\
\text { (years) }\end{array}$ & Complaint & Adrenocortical function* \\
\hline $\mathrm{LCAH}$ & StAR & $\begin{array}{l}\text { (1) c.650 + 2T > A \#, } \\
\text { c.814C > T (p. R272C); } \\
\text { (2)c.707_708delAGinsCTT } \\
\text { (p.K236Tfs), c.772C > T (p.Q258*) }\end{array}$ & $\begin{array}{l}\text { (1) Paternal, } \\
\text { Maternal; } \\
\text { (2) Paternal, } \\
\text { Maternal }\end{array}$ & $\begin{array}{l}\text { (1) } L P, L P \\
\text { (2) } P, L P\end{array}$ & Neonatal & $\begin{array}{l}\text { cyanosis and skin pigmentation } \\
\text { throughout the body }\end{array}$ & $\begin{array}{l}17 \mathrm{OHP} \downarrow / \mathrm{N}, \mathrm{A} 4 \downarrow \downarrow, \mathrm{DHEAS} N, \\
\mathrm{~F} \downarrow / \mathrm{N}, \mathrm{ACTH} \uparrow \uparrow\end{array}$ \\
\hline $11 \beta-O H D$ & CYP11B1 & $\begin{array}{l}\text { c.422G > A (p.R141*), } \\
\text { c.1145 T > C(p.L382P) \# }\end{array}$ & $\begin{array}{l}\text { Maternal, } \\
\text { Paternal }\end{array}$ & LP, VUS & 3.5 & enlarged penis for 3 years & $\begin{array}{l}17 \mathrm{OHP} \uparrow, \mathrm{A} 4 \uparrow \uparrow, \mathrm{DHEAS} \uparrow, \mathrm{T} \\
\uparrow, \mathrm{FN}, \mathrm{ACTH} \uparrow\end{array}$ \\
\hline $\begin{array}{l}3 \beta-H S D \\
\text { deficiency }\end{array}$ & HSD3B2 & $\begin{array}{l}\text { c.674 T > A(p.V225D), } \\
\text { c.776C > T(p.T259M) }\end{array}$ & $\begin{array}{l}\text { Maternal, } \\
\text { Paternal }\end{array}$ & $P, P$ & 9 & enlarged testicles for 5 years & $\begin{array}{l}17 \mathrm{OHP} \uparrow, \mathrm{A} 4 \uparrow \uparrow, \mathrm{DHEAS} \uparrow \uparrow, \\
\mathrm{T} \uparrow, \mathrm{F} \downarrow, \mathrm{ACTH} \uparrow \uparrow\end{array}$ \\
\hline PORD & $P O R$ & $\begin{array}{l}\text { c.1622C > T(p.A541V) \#, } \\
\text { c.1804C > T(p.Q602*) \# }\end{array}$ & $\begin{array}{l}\text { Maternal, } \\
\text { Paternal }\end{array}$ & $L P, L P$ & 2 & $\begin{array}{l}\text { external genital abnormalities for } \\
\text { more than } 1 \text { year }\end{array}$ & $\begin{array}{l}17 \mathrm{OHP} \uparrow, \mathrm{A} 4 \downarrow \downarrow, T \downarrow, F N, \\
\mathrm{ACTH} \downarrow\end{array}$ \\
\hline
\end{tabular}

Note: *See Supplementary Table 2 for details. \# novel variants haven't been reported before; $P$ pathogenic; $L P$ likely pathogenic; VUS variant of uncertain significance; $17 O H P$ 17a-hydroxyprogesterone; $A 4$ androstenedione; $T$ testosterone; DHEAS dehydroepiandrosterone sulfate; $A C T H$ adrenocorticotropic hormone; $F$ cortisol; $\uparrow$, increase; $\downarrow$, decrease; $\uparrow \uparrow$ or $\downarrow \downarrow$, beyond the limits of detection; N, normal 
showed characteristic changes: 11-deoxycortisol and 11deoxycorticosterone levels were significantly increased, accompanied by increasing levels of progesterone, androgen and estrogen, while the levels of 21deoxycortisol, glucocorticoids and mineralocorticoids decreased. In patient with $3 \beta-H S D$ deficiency, DHEA was significantly increased, accompanied by increased $17 \mathrm{OHP}$, progesterone and androgen, while the levels of glucocorticoids and mineralocorticoids were decreased. Patient with PORD was characterized by increased 17OHP and progesterone, while the levels of androgen and glucocorticoids were decreased.

\section{Genetic characteristics}

After gene sequencing, complex heterozygous variants were detected in all patients ( 2 cases were LCAH, $11 \beta$ OHD, 3 $\beta-H S D$ deficiency and PORD each accountingfor 1 case). Among them, one novel variant was detected in the StAR gene $($ c. $650+2 \mathrm{~T}>\mathrm{A})$; one novel variant c. $1145 \mathrm{~T}>\mathrm{C}$ (p. L382P) was detected in the CYP11B1 gene; and two novel variants were detected in the $P O R$ gene, that is c. $1622 \mathrm{C}>\mathrm{T}$ (p. A541V) and c. $1804 \mathrm{C}>\mathrm{T}$ (p. Q602 *). According to the 2015-ACMG Standards and Guidelines, most of the variants in these patients were pathogenic or likely pathogenic variants, which were consistent with their clinical manifestations. See Table 1.

\section{Discussion}

Congenital adrenal hyperplasia $(\mathrm{CAH})$ is a group of diseases caused by steroid hormone synthesis disorders. From 1955 to 2004, the genes for most of the essential enzymes in the steroid hormone synthesis pathway were successively cloned. According to the types of known defective enzymes (genes), $\mathrm{CAH}$ can be divided into 7 types [9-14], including 21-OHD (encoded by CYP21A2 gene), 11 $\beta$-OHD (encoded by CYP11B1 gene), 17-OHD (encoded by CYP17A1 gene), 3ß-HSD deficiency (encoded by HSD3B2 gene), LCAH (encoded by StAR Gene), PORD (encoded by POR gene) and cholesterol side-chain cleavage enzyme deficiency (P450cc deficiency, encoded by CYP11A1 gene).

In steroid hormone cells, adrenal steroid hormone production is a dynamic process that relies on the de novo synthesis of cholesterol in response to the stimulation of ACTH and other regulatory factors $[14,15]$. The first step in steroid production is also the rate-limiting step, cholesterol is first converted to pregnenolone (Preg) by the cholesterol side-chain cleavage enzyme (CYP11A1). This process also relies on the transmembrane transport of cholesterol from the outer mitochondrial membrane to the inner membrane by steroidogenic acute regulatory protein $(S t A R)$. Then, the $17 \alpha-$ hydroxylase activity of $\mathrm{P} 450 \mathrm{C} 17$ (CYP17A1) converts Preg to $17 \alpha$-hydroxypregnenolone (17OHP5). Preg and
17OHP 5 are synthesized by $3 \beta$-hydroxysteroid dehydrogenase 2 (HSD3B2) to produce progesterone and $17 \mathrm{OHP}$, respectively. The latter is catalysedby a series of enzymes such as 21-hydroxylase (CYP21A2) and 11 $\beta$ hydroxylase $(C Y P 11 B 1)$, and then finally produces mineralocorticoids and glucocorticoids.

$\mathrm{CAH}$ caused by $11 \beta-\mathrm{OHD}$ and $3 \beta-\mathrm{HSD}$ deficiency is characterized by hyperandrogenemia, and the clinical manifestations are similar to those of 21-OHD. However, PORD and LCAH may lead to abnormal sexual development and a lack of secondary sexual characteristics due to androgen synthesis disorders. In our study, 2 cases of LCAH were admitted in the neonatal period for "lip cyanosis and skin pigmentation", and were initially misdiagnosed as cardiovascular disease or Addison syndrome initially. Patients with $11 \beta-\mathrm{OHD}$ and $3 \beta-\mathrm{HSD}$ deficiency were diagnosed with $\mathrm{CAH}$ with hyperandrogenism symptoms, and both of them suffered from an enlarged penis, rapid height growth and backward $\mathrm{HtSDS}_{\mathrm{BA}}$; it was not until genetic tests were carried out that their specific disease type was identified. For patient with PORD, she was admitted with "external genital abnormalities" and initially diagnosed with "atypical 21-OHD" initially. Recently, after careful study of her medical history, we felt it's necessary to perform gene sequencing (long PCR + NGS + MLPA) again, and finally confirmed the pathogenic variants of the $P O R$ gene. Pathogenic or possible pathogenic variants were detected in all patients, which were consistent with their clinical manifestations. Among them, one novel variant was detected in the StAR gene $(\mathrm{c} .650+2 \mathrm{~T}>\mathrm{A})$; one novel variant c. $1145 \mathrm{~T}>\mathrm{C}$ (p. L382P) was detected in the $C Y P 11 B 1$ gene; and two novel variants were detected in the POR gene, that is c. $1622 \mathrm{C}>\mathrm{T}$ (p. A541V) and c.1804C > T (p. Q602 *).

The concentration of steroid hormones in organisms is very low, generally calculated in units of $\mathrm{nmol} / \mathrm{L}$ and $\mathrm{pmol} / \mathrm{L}$, and there are many kinds of steroid compounds with similar structure [16-18]. Due to the influence of antigen-antibody cross reaction and poor specificity, the detection result of steroid hormones by immunoassay might be higher than the actual level, which may lead to improper drug replacement therapy. In many complex adrenal diseases, including $\mathrm{CAH}$, the ratio or relative change of multiple steroid hormones is more important than the value of any one steroid hormone $[19,20]$. In recent years, with the widespread application of LC-MS/ MS in clinical medicine [21-23], LC-MS/MS can detect nearly 20 types in steroid hormones at the same time. Through the relative changes of hormone levels, it can initially verify the diagnosis and classification of $\mathrm{CAH}$, which is helpful for early diagnosis and timely treatment [24, 25]. In our study, the LC-MS/MS results for steroid hormones in patients were also consistent with their 


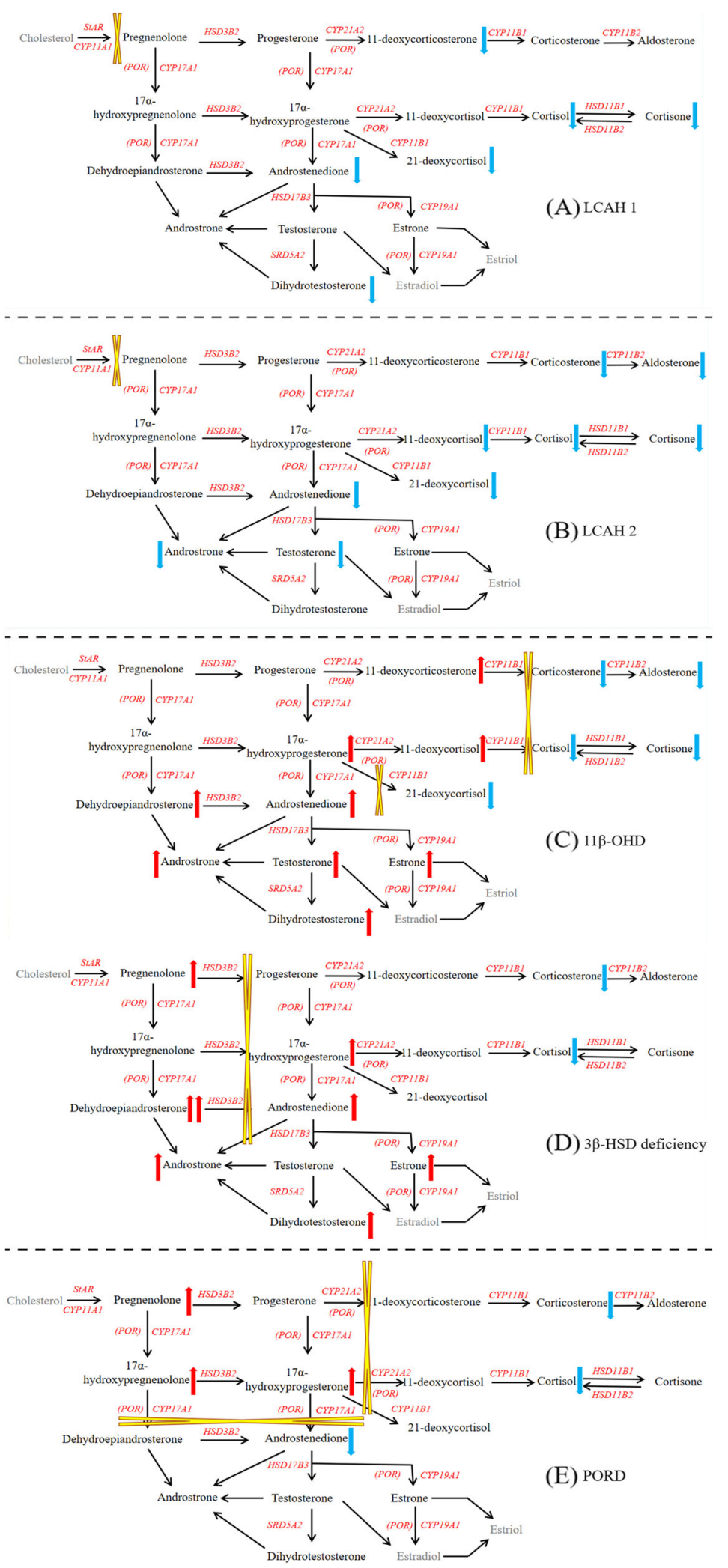

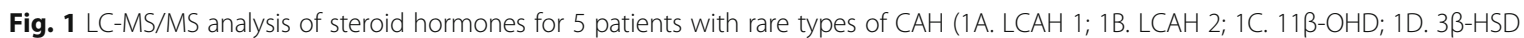
deficiency; 1E. PORD) 
genetic variants: 2 patients with LCAH showed a decrease in all steroid hormones; 11ß-OHD patient showed a significant increase in 11-deoxycortisol and 11deoxycorticosterone; patient with $3 \beta$-HSD deficiency showed a significant increase in DHEA; and PORD patient was mainly characterized by elevated $17 \mathrm{OHP}$, progesterone and impaired synthesis of androgen levels. The above results indicate that the results of LC-MS/MS in patients with $\mathrm{CAH}$ are in good agreement with the results of gene sequencing; through the change spectrum of the steroid hormones, we can preliminarily judge the possible positions of defective enzymes in CAH patients and make an initiatory judgement on its typing.

Due to the location of enzyme defects, the clinical manifestations of different types of $\mathrm{CAH}$ are complex and changeable, the prognosis and treatments will also be different. CAH caused by $11 \beta-O H D$ and $3 \beta-H S D$ is often characterized by hyperandrogenism, which is likely to cause problems such as advanced BA and precocious puberty and may need to be treated with gonadotrophin-releasing hormone agonists [26]; while PORD and LCAH often have androgen synthesis disorders and then lack of secondary sexual characteristics, they may require sex hormone to induce development after puberty. Therefore, the clinical diagnosis of $\mathrm{CAH}$ cannot be too indistinct, and it's necessary to clarify the specific classification to better judge the prognosis and guide treatment.

\section{Conclusions}

Our study summarized the clinical characteristics (clinical manifestations, auxiliary examinations and diagnosis, etc.) of 5 cases of rare CAH. In our study, we detected 4 novel variants that have not been reported before, which enriched the variant spectrum of the CAH gene. We also found that compared with immunoassay, the use of LCMS/MS to detect steroid hormones can greatly improve the positive predictive value of $\mathrm{CAH}$ diagnosis, and the comprehensive analysis of multiple steroid hormones by LC-MS/MS can also help in the diagnosis and classification of $\mathrm{CAH}$. The treatment goal of $\mathrm{CAH}$ has gradually changed from preventing the occurrence of crisis to ensuring normal growth and development as much as possible. It's believed that LC-MS/MS will play an increasingly important role in the clinical application of $\mathrm{CAH}$ with further research.

\footnotetext{
Abbreviations

CAH: Congenital adrenal hyperplasia; 21-OHD: 21-hydroxylase deficiency; 11ß-OHD: $11 \beta$-hydroxylase deficiency; $3 \beta$-HSD deficiency: $3 \beta$-hydroxysteroid dehydrogenase deficiency; LCAH: Lipoid congenital adrenal hyperplasia; PORD: P450 oxidoreductase deficiency; StAR: Steroidogenic acute regulatory protein; BA: Bone age; $\mathrm{HtSDS}_{\mathrm{BA}}$ : Height standard deviation score for BA; PCR: Polymerase chain reaction; NGS: Next-generation sequencing; ACTH: Adrenocorticotropic hormone; F: Cortisol; 17OHP: 17a-
}

hydroxyprogesterone; A4: Androstenedione; T: Testosterone; DHEA

S: Dehydroepiandrosterone sulfate

\section{Supplementary Information}

The online version contains supplementary material available at https://doi. org/10.1186/s12902-021-00901-8.

\section{Additional file 1:. \\ Additional file 2:. \\ Additional file 3:.}

\section{Acknowledgements}

We would like to thank the patients and his parents for participating in this work.

\section{Authors' contributions}

XPL conceptualized and designed the study. ZGL supervised the data collection, reviewed the analyses and wrote all versions of the manuscript. YL, CQD, YX, LH, WW and YQY coordinated and supervised data collection, critically reviewed the manuscript and approved the final manuscript as submitted. All authors contributed to the article and approved the submitted version.

\section{Funding}

No funding was secured for this study.

\section{Availability of data and materials}

The dataset analyzed in the current study is available from the corresponding author upon reasonable request.

\section{Declarations}

Ethics approval and consent to participate

This study was approved by the Ethics Committee of Tongji Hospital, Tongji Medical College, Huazhong University of Science and Technology (Approval number: TJ-IRB20180703) and adhered to the tenets of the Declaration of Helsinki. Informed written consent was obtained from the parents of the patient.

Consent for publication

Written informed consent to publish was obtained from each participant.

\section{Competing interests}

All authors declare that they have no conflict of interest.

\section{Author details}

${ }^{1}$ Department of Pediatrics, Tongji Hospital, Tongji Medical College, Huazhong University of Science and Technology, Wuhan, China. ${ }^{2}$ Department of Endocrinology, Shenzhen Children's Hospital, Shenzhen, China.

Received: 16 July 2021 Accepted: 17 November 2021

Published online: 25 November 2021

\section{References}

1. Du ML. Consensus statement on diagnosis and treatment of congenital adrenal hyperplasia due to 21-hydroxylase deficiency (Chinese). Zhonghua Erke Zazhi. 2016;54(8):569-76.

2. Speiser PW, Arlt W, Auchus RJ, Baskin LS, Conway GS, Merke DP, et al. Congenital adrenal hyperplasia due to steroid 21-hydroxylase deficiency: an Endocrine Society clinical practice guideline. J Clin Endocrinol Metab. 2018; 103(11):4043-88.

3. Li Z, Huang L, Du C, Zhang C, Zhang M, Liang Y; et al. Analysis of the Screening Results for Congenital Adrenal Hyperplasia Involving 7.85 Million Newborns in China: A Systematic Review and Meta-Analysis.2021; 12:365.

4. El-Maouche D, Arlt W, Merke DP. Congenital adrenal hyperplasia. Lancet. 2017;390(10108):2194-210.

5. Krone N, Arlt W. Genetics of congenital adrenal hyperplasia. Best Pract Res Clin Endocrinol Metab. 2009;23(2):181-92. 
6. Xu Z, Chen W, Merke DP, McDonnell NB. Comprehensive mutation analysis of the CYP21A2 gene: an efficient multistep approach to the molecular diagnosis of congenital adrenal hyperplasia. J Mol Diagn. 2013;15(6):745-53.

7. Janzen N, Riepe FG, Peter M, Sander S, Steuerwald U, Korsch E, et al. Neonatal screening: identification of children with $11 \beta$-hydroxylase deficiency by second-tier testing. Horm Res Paediat. 2012;77(3):195-9.

8. Richards S, Aziz N, Bale S, Bick D, Das S, Gastier-Foster J, et al. Standards and guidelines for the interpretation of sequence variants: a joint consensus recommendation of the American College of Medical Genetics and Genomics and the Association for Molecular Pathology. Genet Med. 2015; 17(5):405-24.

9. White PC, Dupont J, New MI, Leiberman E, Hochberg Z, Rösler A. A mutation in CYP11B1 (Arg-448----his) associated with steroid 11 betahydroxylase deficiency in Jews of Moroccan origin. J Clin Invest. 1991;87(5): 1664-7.

10. Lin D, Sugawara T, Strauss JF 3rd, Clark BJ, Stocco DM, Saenger P, et al. Role of steroidogenic acute regulatory protein in adrenal and gonadal steroidogenesis. Science. 1995;267(5205):1828-31.

11. Tajima T, Fujieda K, Kouda N, Nakae J, Miller WL. Heterozygous mutation in the cholesterol side chain cleavage enzyme (p450scc) gene in a patient with 46,XY sex reversal and adrenal insufficiency. J Clin Endocrinol Metab2001; 86(8):3820-3825.

12. Arlt W, Walker EA, Draper N, Ivison HE, Ride JP, Hammer F, et al. Congenital adrenal hyperplasia caused by mutant P450 oxidoreductase and human androgen synthesis: analytical study. Lancet. 2004;363(9427):2128-35.

13. Kagimoto M, Winter JSD, Kagimoto K, Simpson ER, Waterman MR. Structural characterization of Normal and mutant human steroid 17a- hydroxylase genes: molecular basis of one example of combined 17a- hydroxylase/17,20 Lyase deficiency. Mol Endocrinol. 1988;2(6):564-70.

14. Eberlein WR, Bongiovanni AM. Partial characterization of urinary adrenocortical steroids in adrenal hyperplasia. J Clin Invest. 1955;34(8):133743.

15. Wilkins $L$, Lewis RA, Klein R, Rosemberg E. The suppression of androgen secretion by cortisone in a case of congenital adrenal hyperplasia. Bull Johns Hopkins Hosp. 1950;86(4):249-52.

16. Rege J, Turcu AF, Else T, Auchus RJ, Rainey WE. Steroid biomarkers in human adrenal disease. J Steroid Biochem. 2019;190:273-80.

17. Miller WL, Bose HS. Early steps in steroidogenesis: intracellular cholesterol trafficking. J Lipid Res. 2011;52:2111-35.

18. Porter FD, Herman GE. Malformation syndromes caused by disorders of cholesterol synthesis. J Lipid Res. 2011;52:6-34.

19. Gouveia MJ, Brindley PJ, Santos LL. Correia da Costa JM, Gomes P, Vale N. mass spectrometry techniques in the survey of steroid metabolites as potential disease biomarkers: a review. Metabolism. 2013;62(9):1206-17.

20. Wooding KM, Auchus RJ. Mass spectrometry theory and application to adrenal diseases. Mol Cell Endocrinol. 2013;371(1):201-7.

21. Janzen N, Peter M, Sander S, Steuerwald U, Terhardt M, Holtkamp U, et al Newborn screening for congenital adrenal hyperplasia: additional steroid profile using liquid chromatography-tandem mass spectrometry. J Clin Endocrinol Metab. 2007;92(7):2581-9.

22. Schwarz E, Liu A, Randall H, Haslip C, Keune F, Murray M, et al. Use of steroid profiling by UPLC-MS/MS as a second tier test in newborn screening for congenital adrenal hyperplasia: the Utah experience. Pediatr Res. 2009; 66(2):230-5

23. Gosetti F, Mazzucco E, Gennaro MC, Marengo E. Ultra high performance liquid chromatography tandem mass spectrometry determination and profiling of prohibited steroids in human biological matrices. A review J Chromatogr B. 2013;927:22-36.

24. Fiet J, Le Bouc Y, Guéchot J, Hélin N, Maubert M-A, Farabos D, et al. A liquid chromatography/tandem mass Spectometry profile of 16 serum steroids, including 21-Deoxycortisol and 21-Deoxycorticosterone, for management of congenital adrenal hyperplasia. J Endocrinol. 2017;1(3):186-201.

25. Dahl SR, Nermoen I, Brønstad I, Husebye ES, Løvås K, Thorsby PM. Assay of steroids by liquid chromatography-tandem mass spectrometry in monitoring 21-hydroxylase deficiency. Endocr Connect. 2018;7(12):1542-50.

26. Quintos JB, Vogiatzi MG, Harbison MD, New MI. Growth hormone therapy alone or in combination with gonadotropin-releasing hormone analog therapy to improve the height deficit in children with congenital adrenal hyperplasia. J Clin Endocrinol Metab. 2001;86(4):1511-7.

\section{Publisher's Note}

Springer Nature remains neutral with regard to jurisdictional claims in published maps and institutional affiliations.

\section{Ready to submit your research? Choose BMC and benefit from:}

- fast, convenient online submission

- thorough peer review by experienced researchers in your field

- rapid publication on acceptance

- support for research data, including large and complex data types

- gold Open Access which fosters wider collaboration and increased citations

- maximum visibility for your research: over $100 \mathrm{M}$ website views per year

At BMC, research is always in progress.

Learn more biomedcentral.com/submissions 